\title{
10 MW Wind Turbine Direct-Drive Generator Design with Pitch or Active Speed Stall Control
}

\author{
H. Polinder, D. Bang \\ Electrical Power Processing / DUWIND \\ Delft University of Technology \\ Mekelweg 4, 2628 CD Delft \\ The Netherlands
}

\author{
R.P.J.O.M. van Rooij \\ Wind Energy Research / DUWIND \\ Delft University of Technology \\ Kluyverweg 1, 2629 HS Delft \\ The Netherlands
}

\author{
A.S. McDonald, M.A. Mueller \\ Institute for Energy Systems \\ The University of Edinburgh \\ Kings Buildings, Mayfield Road, \\ Edinburgh, EH9 3JL, United Kingdom
}

\begin{abstract}
The objectives of this paper are to investigate the feasibility of a $10 \mathrm{MW}$ generator for a direct-drive wind turbine and to compare the generator systems for pitch control and for active speed stall control. The idea behind the active speed stall control concept is to make a rotor that is as simple as possible, and therefore very robust and suitable for offshore wind turbines. This is done by removing the pitch control of the blades. Above rated wind speed, the power is not controlled by controlling the pitch, but by controlling the rotor speed: the rotor speed is so much reduced that the aerodynamic power is limited to the rated value. A rough $10 \mathrm{MW}$ permanent-magnet directdrive generator design is presented, indicating that such a generator is feasible. It is shown that for a thorough evaluation of active speed stall control, more knowledge is required about changes in the wind speed. However, a considerable increase in generator system cost is necessary to enable active speed stall control.
\end{abstract}

Index Terms-wind turbine, synchronous generator, permanent-magnet generator, direct-drive

\section{INTRODUCTION}

The objectives of this paper are to investigate the feasibility of a $10 \mathrm{MW}$ generator for a direct-drive wind turbine and to compare the generator systems for pitch control and for active speed stall control.

To investigate the feasibility of a $10 \mathrm{MW}$ direct-drive generator, a rough design is made. Is such a generator realistic, or is it so incredibly large and expensive that it is not viable? To investigate this, both a mechanical construction and an electromagnetic design are proposed.

The idea behind the active speed stall control concept is to make a wind turbine that is as simple as possible, and therefore very robust and suitable for offshore wind parks. Therefore, a number of design choices has been made:

- The rotor blades can not pitch and, therefore, there is no pitch control.

- The blades are designed to maximize aerodynamic performance at wind speeds below rated.

- $\quad$ A direct-drive permanent-magnet generator is used.

This work was supported in part by the European Community's Sixth Framework Programme (FP6) under contract no 019945 (SES6), an Integrated Project named UPWIND, and in part by SenterNovem under contract number KIEM03028, a project named ICORASS.
- The aerodynamic performance at wind speeds above rated is limited by actively controlling the rotor speed. This means that if the wind speed increases to values above rated, the generator reduces the rotor speed of the wind turbine so that not more than rated power is produced.

It is not new to use wind turbines without pitch control. Until the late 1990s, many wind turbine manufacturers built constant speed wind turbines with power levels below 1.5 MW with stall control, which means that the blades can not pitch $[1,2]$. However, the aerodynamic performance of the blades of these turbines is not optimum because the design of the blades is a compromise between maximum aerodynamic efficiency at wind speeds below rated and limited aerodynamic efficiency (resulting in a roughly constant output power) at wind speeds above rated. What is new in the active speed stall control concept is that the power is controlled by active speed control.

It is also not new to use a direct-drive permanent magnet generator. For example, the Z72 [3] of Harakosan Europe BV is a wind turbine with a direct-drive permanent-magnet generator. However, it is new that the generator discussed in this paper is used to control the rotor speed and the power without using pitch control.

In this paper, the consequences of the active speed stall control design choices are investigated. Must the generator be over-dimensioned in order to be able to make the required torque at increasing wind speeds, and if yes, how much must it be over-dimensioned? Will the annual energy yield be influenced by these design choices, and if yes, how much? This is mainly done by comparing the direct-drive generator systems for active speed stall control and pitch control.

The contributions of this paper are that it presents a feasibility study of $10 \mathrm{MW}$ direct-drive generators and that it compares the generator systems for pitch control and for active speed stall control.

The paper is organized as follows. First, the wind turbine characteristics and the properties of the two different control concepts are discussed. Next, the generator system design is discussed for the two control concepts. Subsequently, the performance of the two different control strategies is discussed. Finally, some conclusions are drawn. 


\section{WIND TURBINE DESCRIPTION AND CONTROL}

\section{A. Wind turbine description}

Table I gives some dimensions and characteristics of the 10 MW wind turbine considered in this paper. Using these characteristics, the available shaft power can be calculated as a function of the wind speed as [2], [4],

$$
P=\frac{1}{2} \rho_{\text {air }} C_{p}(\lambda, \theta) \pi r^{2} v_{w}^{3}
$$

where

$\rho_{\text {air }}$ is the mass density of air,

$r \quad$ is the wind turbine rotor radius,

$v_{w} \quad$ is the wind speed, and

$C_{p}(\lambda, \theta)$ is the power coefficient or the aerodynamic efficiency, which is a function the of tip speed ratio $\lambda$ (tip speed divided by wind speed) and the pitch angle $\theta$.

Fig. 1 gives the calculated power and torque curves of this wind turbine at different rotor speeds. In this figure, the pitch angle is zero. The aerodynamic performance calculations for the wind turbine are based on a blade-element-momentum (BEM) theory code, comparable to the well-known PROPCODE [5]. The blade design is similar to the current large multi-megawatt rotor designs and the aerodynamic input is corrected for augmented lift due to rotation. This is in particular important for the inboard span locations which now contributes to a larger extend to the overall power. Twodimensional stall of the segment lift curves is now delayed and lift and stall angle are increased. Furthermore, at larger angles of attack where full turbulent separation from the nose is expected a gradual decrease of lift is applied similar to the method of [6]. This approach was derived through validation of a number of stall regulated turbines and worked well in those cases.

\section{B. Wind turbine control}

The power coefficient of (1) is maximum at a constant tip speed ratio $[2,4]$. Therefore, below rated wind speeds, the rotor speed is made proportional to the wind speed to obtain maximum energy yield.

The turbine with pitch control pitches the blades to reduce the power coefficient at wind speeds above rated to keep the rotor speed more or less constant at the rated rotor speed and to produce a constant output power.

The turbine with active speed stall control is controlled by reducing the rotor speed at wind speeds above rated. The rotor speed is limited in order to limit the output power. There are a number of possible ways to control the rotor speed of a wind turbine with active speed control. To explain some extreme possibilities, we use the power curves of Fig.1.

If the generator system has an unlimited power and torque rating, the rotor speed can be controlled. For example, if the wind speed is $12 \mathrm{~m} / \mathrm{s}$ and the rotor speed is $10 \mathrm{rpm}$, the output power is about $10 \mathrm{MW}$. If the wind speed instantaneously increases from 12 to $24 \mathrm{~m} / \mathrm{s}$, the power nearly instantaneously increases to about $25 \mathrm{MW}$. If the generator system is able to make a power larger that $25 \mathrm{MW}$, the generator is able to reduce the rotor speed to $7 \mathrm{rpm}$ so that the output power is about $10 \mathrm{MW}$ again. However, implementing a $25 \mathrm{MW}$ generator system in a $10 \mathrm{MW}$ wind turbine is probably too expensive.

TABLE I

MODELING CHARACTERISTICS

\begin{tabular}{|l|r|}
\hline \multicolumn{2}{|c|}{ wind turbine characteristics } \\
\hline rated grid power $(\mathrm{MW})$ & 10 \\
\hline rotor diameter $(\mathrm{m})$ & 170 \\
\hline rated wind speed $(\mathrm{m} / \mathrm{s})$ & 12 \\
\hline rated rotor speed $(\mathrm{rpm})$ & 10 \\
\hline optimum tip speed ratio (blade tip speed divided by wind speed) & 9.5 \\
\hline maximum aerodynamic rotor efficiency $(\%)$ & 51.5 \\
\hline mass density of air $\left(\mathrm{kg} / \mathrm{m}^{3}\right)$ & 1.225 \\
\hline
\end{tabular}
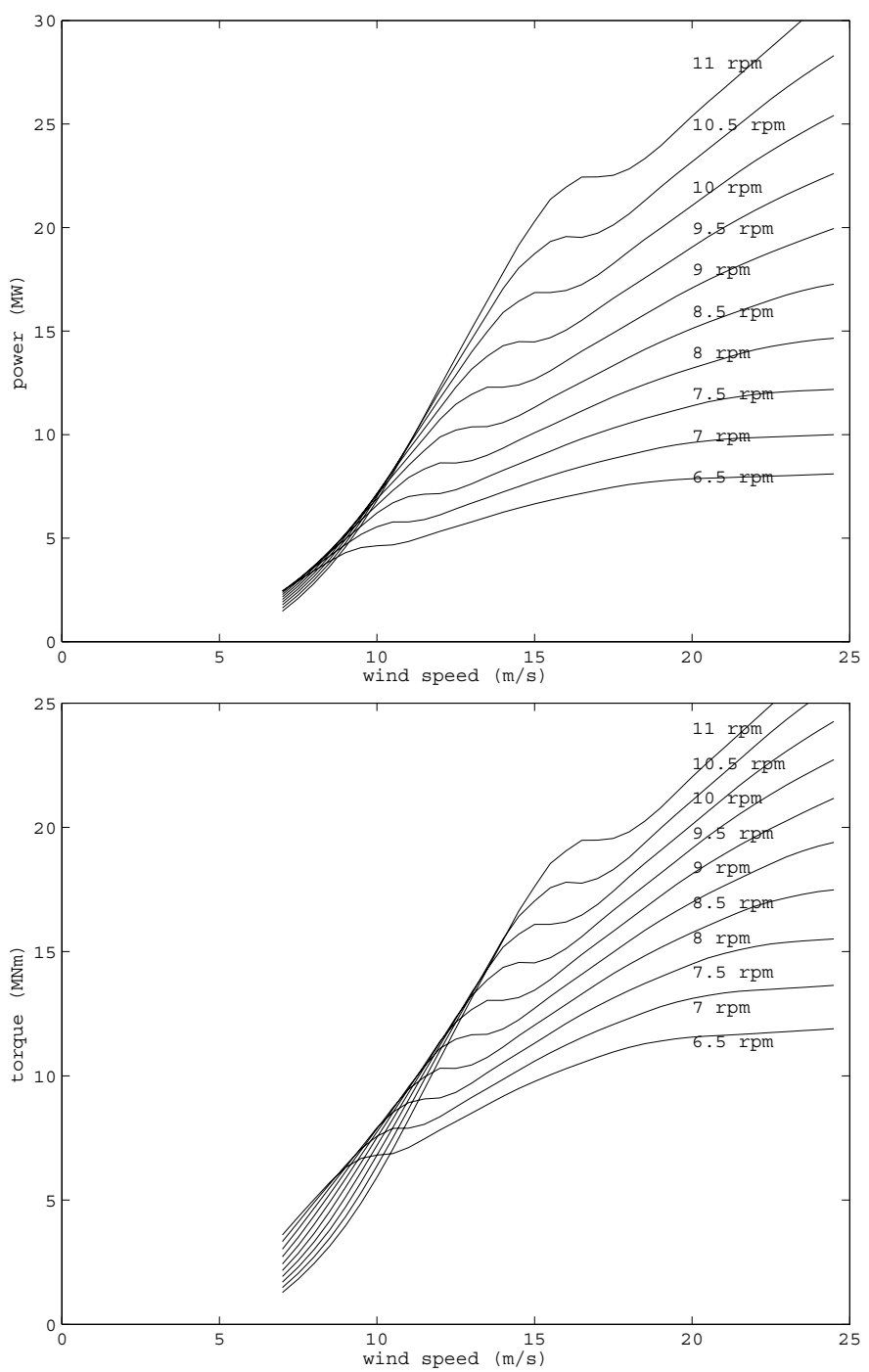

Fig. 1: Power and torque curves of the ICORASS turbine at constant rotor speeds of $6.5,7,7.5,8,8,5,9,9.5,10,10.5$ and $11 \mathrm{rpm}$. 
A safe way of operating the wind turbine is by keeping the rotor speed so low that the power never exceeds $10 \mathrm{MW}$. According to the power curves of Fig. 1, this means that the rotor speed has to be limited to roughly $7 \mathrm{rpm}$, because at this rotor speed the power is limited to $10 \mathrm{MW}$ for all wind speeds and all changes in wind speed. However, this probably results in a rather low energy yield.

If the wind speed is known in advance, the rotor speed can be reduced before the wind speed increases. In that way, a 10 MW generator system can be used. For example, if it is known that in 60 seconds, the wind speed will instantaneously increase to $24 \mathrm{~m} / \mathrm{s}$, the rotor speed can be reduced to $7 \mathrm{rpm}$ in 60 seconds. After the rotor speed has been reduced, the increase in the wind speed does not harm the wind turbine. However, predicting the wind speed is not that easy.

It is very unlikely that the wind speed will instantaneously increase from 12 to $24 \mathrm{~m} / \mathrm{s}$. If the increase of the wind speed is limited, it is possible to design a generator system and a control that adapts the rotor speed based on the measured rotor speed. However, relying on such a control system is critical, because a faster increase of the wind speed than expected would lead to the problem that the generator system is not able to reduce the rotor speed, and then the rotor speed will increase, which results in a further increase in the power, which will destroy the turbine if the wind speed does not reduce again.

In this paper, the generator system is adapted in two ways to make active speed stall control possible.

- The maximum rotor speed is limited to $9 \mathrm{rpm}$.

- The torque level of the generator system is increased by $40 \%$.

In this way, the generator system can deliver $10 \mathrm{MW}$ at a wind speed of $25 \mathrm{~m} / \mathrm{s}$ and a rotor speed of $7 \mathrm{rpm}$. Further, the generator can deliver $10 \mathrm{MW}$ at $9 \mathrm{rpm}$ with a substantial torque margin to reduce the rotor speed when the wind speed increases.

It is assumed that increasing the torque level of the generator to $14 \mathrm{MNm}$ and reducing the rotor speed to $9 \mathrm{rpm}$ is sufficient to guarantee safe operation. However, more research is necessary to validate this assumption.

- It should be investigated further which wind speed changes can be expected.

- It should be investigated further how well these wind speed changes can be predicted.

\section{Direct-Drive Generator DESIGN}

\section{A. Electromagnetic design}

In this paper, direct dive generators are considered because direct drive generators eliminate the maintenance and the problems of gearboxes.

The generator is a permanent magnet generator. Several studies [6-11] identified this type of generator as the most suitable for direct-drive generators for wind turbines because this generator has a high force density, a high efficiency and a reasonable cost.

The generator dimensions are determined based on a force density of $40 \mathrm{kN} / \mathrm{m}^{2}[12,13]$. At this value of the force density, the losses in the generator are in the order of $6 \mathrm{~kW} / \mathrm{m}^{2}$. It should be possible to dissipate this amount of heat by using proper air cooling [3]. For an air gap diameter of $10 \mathrm{~m}$, this results in a stack length of $1.6 \mathrm{~m}$ for the pitch controlled machine and a stack length of $2.24 \mathrm{~m}$ for the active speed stall controlled machine. In both cases, the aspect ratio (ratio of stack length to air gap diameter) is in the order of 0.2 , which is quite close to optimum according to [14].

The air gap is $10 \mathrm{~mm}$, which is $0.1 \%$ of the air gap diameter, as proposed in e.g. [9].

Fig. 2 gives a cross section of four pole pitches of the permanent-magnet machine. Dimensions are given in table II. A full pitch winding with one slot per pole per phase is used. This choice leads to a small pole pitch compared to the axial length, and therefore to rather narrow coils. There are a number of reasons for using these small pole pitches.

- Using larger pole pitches results in thicker yokes and therefore in increasing generator weights.

- Using larger pole pitches increases the risk of demagnetization of the magnets. In case of a small pole pitch, the magnetic field due to the currents remains small compared to the field of the magnets, and the main inductance remains smaller than the leakage inductance.

- Using larger poles pitches increases the copper losses in the end windings without increasing the induced voltages.

Fractional pitch concentrated winding in the stator are not used, because this would result in considerable eddy currents in the magnets and the back-iron [15].

In order to get a reasonable flux density level in the air gap of $10 \mathrm{~mm}$, the magnet length in the direction of magnetization is chosen $20 \mathrm{~mm}$. The tooth width and the slot width are equal. This results in a reasonable flux density level in the teeth and leaves space for copper in the slots. The slots are rather deep to reduce the copper losses.

The analytical expressions used for calculating the parameters of the machine (the no-load voltage, the inductances and the resistance) have been mentioned in [7] and therefore, they are not repeated here.

The resulting dimensions and weights are given in table II.

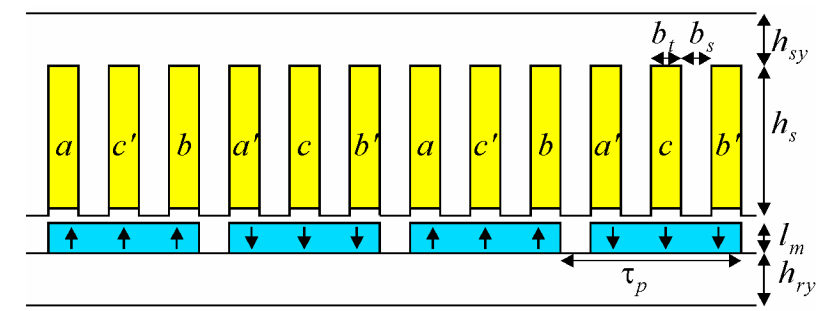

Fig. 2. Sketch of a linear cross-section of four poles of a permanent magnet synchronous machine with full pitch winding. 


\section{B. Mechanical construction}

Fig. 3 depicts a possible generator construction design as proposed in [14]. In this construction design, gravity forces and magnetic attraction forces between rotor and stator are considered. Deflections of up to $1 \mathrm{~mm}$ are allowed for both the stator and the rotor construction. Deformation of the mechanical structure due to wind loads has not been considered, because this deformation depends a lot on the construction of the rest of the turbine. The weight of this construction is 260 ton for the generator with pitch control and 407 ton for the generator with active speed stall control.

Probably, by using more sophisticated construction methods, this weight can be reduced. An example of a more sophisticated construction is the construction of the Harakosan Europe BV [3] generator depicted in Fig. 4.

For our feasibility study, it indicates that such a generator is large and expensive, but not unrealistic when compared to weights of other generator systems for wind turbines.

Further, it can be concluded that the generator system for the turbine with active speed stall control is much heavier and more expensive than the generator system of the turbine with pitch control.

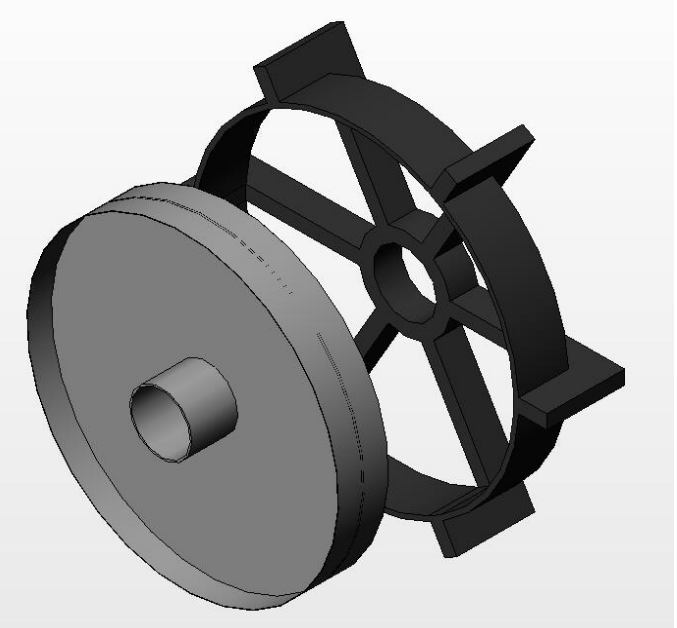

Fig. 3. Sketch of a possible construction of the permanent-magnet generator.

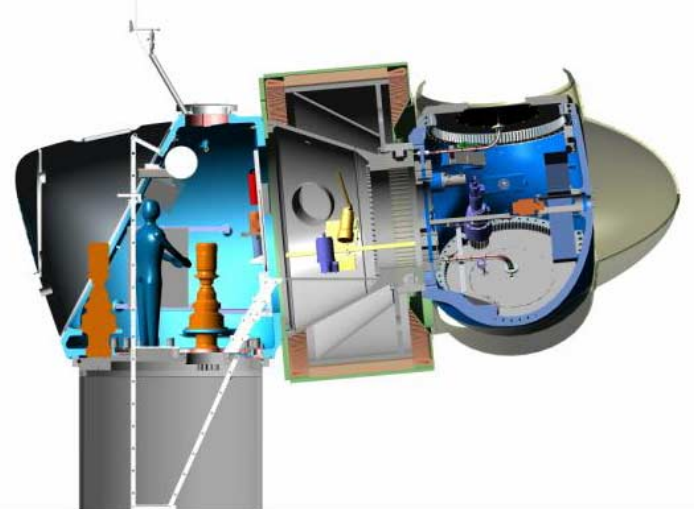

Fig. 4. Sketch of the more sophisticated construction of the permanent-magnet direct-drive generator oft the Z72 [3] of Harakosan Europe BV.

\section{Power electronic converter}

A power electronic converter is used for the grid connection. A back-to-back voltage source inverter is used.

The applied phasor diagram is depicted in Fig. 5. The current phasor is placed between the phasors for the voltage induced by the permanent magnets and the terminal voltage. This results in a reasonable power factor for both the machine and the power electronic converter. For the turbine with pitch control, the turbine power is limited to $10 \mathrm{MW}$ by pitching the blades. Therefore, the generator torque rating is $10 \mathrm{MNm}$. The power rating of the power electronic converter is chosen 11 MVA because the power factor is below one.

TABLE II

GENERATOR SYSTEM PROPERTIES, DIMENSIONS AND WEIGHT

\begin{tabular}{|c|c|c|}
\hline control concept & pitch & $\begin{array}{l}\text { active } \\
\text { speed stall }\end{array}$ \\
\hline \multicolumn{3}{|l|}{ Generator characteristics } \\
\hline Slot filling factor $k_{s f i}$ & 0.65 & 0.65 \\
\hline $\begin{array}{l}\text { remanent flux density of the magnets } B_{r m} \text { at operating } \\
\text { temperature }(\mathrm{T})\end{array}$ & 1.2 & 1.2 \\
\hline recoil permeability of the magnets $\mu_{r m}$ & 1.06 & 1.06 \\
\hline resistivity of copper at operating temperature $\rho_{C u}(\mu \Omega \mathrm{m})$ & 0.025 & 0.025 \\
\hline $\begin{array}{l}\text { eddy-current losses in laminations at } 1.5 \mathrm{~T} \text { and } 50 \mathrm{~Hz} \\
P_{F e O e}(\mathrm{~W} / \mathrm{kg})\end{array}$ & 0.5 & 0.5 \\
\hline $\begin{array}{l}\text { hysteresis losses in laminations at } 1.5 \mathrm{~T} \text { and } 50 \mathrm{~Hz} P_{F e O h} \\
(\mathrm{~W} / \mathrm{kg})\end{array}$ & 2 & 2 \\
\hline \multicolumn{3}{|l|}{ maximum losses in the converter } \\
\hline maximum losses in the converter $P_{\text {convm }}(\mathrm{kW})$ & 300 & 378 \\
\hline \multicolumn{3}{|l|}{ cost modeling } \\
\hline power electronics cost $(€ / \mathrm{kW})$ & 40 & 40 \\
\hline laminations cost $(€ / \mathrm{kg})$ & 3 & 3 \\
\hline copper cost $(€ / \mathrm{kg})$ & 15 & 15 \\
\hline magnet cost $(€ / \mathrm{kg})$ & 25 & 25 \\
\hline \multicolumn{3}{|l|}{ generator dimensions } \\
\hline stator radius $r_{s}(\mathrm{~m})$ & 5 & 5 \\
\hline stack length $l_{s}(\mathrm{~m})$ & 1.6 & 2.24 \\
\hline number of pole pairs $p$ & 160 & 160 \\
\hline number of slots per pole per phase $q$ & 1 & 1 \\
\hline air gap $g(\mathrm{~mm})$ & 10 & 10 \\
\hline stator slot width $b_{s s}(\mathrm{~mm})$ & 16.4 & 16.4 \\
\hline stator tooth width $b_{s t}(\mathrm{~mm})$ & 16.4 & 16.4 \\
\hline stator slot height $h_{s s}(\mathrm{~mm})$ & 80 & 80 \\
\hline stator yoke height $h_{s y}(\mathrm{~mm})$ & 40 & 40 \\
\hline rotor yoke height $h_{r y}(\mathrm{~mm})$ & 40 & 40 \\
\hline magnet height $l_{m}(\mathrm{~mm})$ & 20 & 20 \\
\hline rotor pole width $b_{p}(\mathrm{~mm})$ & 80 & 80 \\
\hline \multicolumn{3}{|l|}{ generator material weight (ton, $1000 \mathrm{~kg}$ ) } \\
\hline laminations (ton) & 47 & 65 \\
\hline copper (ton) & 12 & 17 \\
\hline PM (ton) & 6 & 9 \\
\hline construction (ton) & 260 & 407 \\
\hline total (ton) & 325 & 498 \\
\hline \multicolumn{3}{|l|}{ ratings } \\
\hline generator torque $(\mathrm{MNm})$ & 10 & 14 \\
\hline generator power (MVA) & 11 & 13.9 \\
\hline converter (MVA) & 11 & 13.9 \\
\hline \multicolumn{3}{|l|}{$\operatorname{cost}(\mathrm{M} €)$} \\
\hline generator active material & 0.46 & 0.64 \\
\hline generator construction material & 0.78 & 1.22 \\
\hline Converter & 0.40 & 0.50 \\
\hline total & 1.64 & 2.36 \\
\hline
\end{tabular}


For the turbine with active stall speed control, the generator torque rating is $14 \mathrm{MNm}$. This torque rating determines the maximum current the generator and the converter have to be rated for. The generator rotor speed rating is $9 \mathrm{rpm}$. This rotor speed rating determines the voltage level of the converter. Including a $10 \%$ margin for the power factor that is below one lead to a converter rating of $13.9 \mathrm{MW}$. In steady-state, this power level is not reached but this gives the turbine a safety margin for decreasing the rotor speed when the wind speed is increasing.

The losses in the power electronic converter are modelled in the same way as in [7]. It is assumed that at rated power, the losses are $3 \%$ of the rated power, that is $300 \mathrm{~kW}$ for the turbine with pitch control, and $378 \mathrm{~kW}$ for the turbine with active speed stall control. It is further assumed that the cost of a power electronic converter is $40 \mathrm{k} € / \mathrm{MW}$.

\section{PERformance COMPARISON}

For energy yield calculations, an average wind speed of 10 $\mathrm{m} / \mathrm{s}$ with a Weibull distribution [7] is used.

\section{A. Pitch Control}

Fig. 5 illustrates the steady-state operation characteristics of this turbine with pitch control. At low wind speeds, the turbine is operated at maximum aerodynamic efficiency up to the rated rotor speed of $10 \mathrm{rpm}$; at high wind speeds, the pitch control keeps the rotor speed at $10 \mathrm{rpm}$.

By integrating the area below the graph of energy as a function of wind speed, the annual energy yield can be obtained. From this graph, it can be concluded that in this wind regime, the annual energy yield could be increased considerably by increasing the generator system power. Table III gives the annual energy yield for this control principle.

\section{B. Active speed stall control}

In this control concept, the power is limited to $10 \mathrm{MW}$. As explained in section II, it is assumed that the wind speed changes are slow, or that the wind speed changes are known sufficiently long before they happen. Fig. 7 illustrates the steady-state operation characteristics of this control concept with limited power. At low wind speeds, the turbine is operated at maximum aerodynamic efficiency up to the rated rotor speed of $9 \mathrm{rpm}$. At higher wind speeds, this rotor speed is kept constant, until the power level of $10 \mathrm{MW}$ is reached. Then the rotor speed is reduced to limit the power to $10 \mathrm{MW}$. In order to keep the power at $10 \mathrm{MW}$ at decreasing rotor speeds, the torque and the current have to increase.

Table III gives the annual energy yield for this control principle. The annual energy yield is comparable to the energy yield with pitch control.
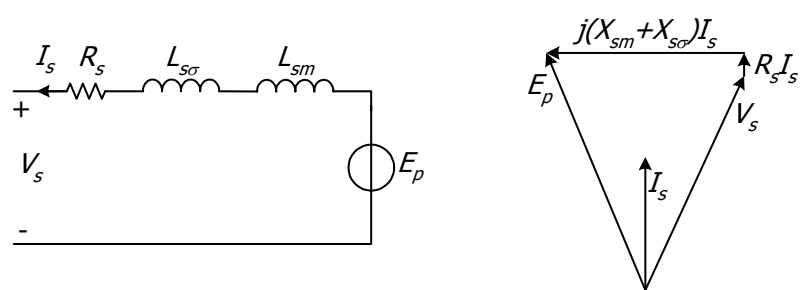

Fig. 5. Equivalent circuit of the permanent-magnet synchronous machine and the applied phasor diagram.
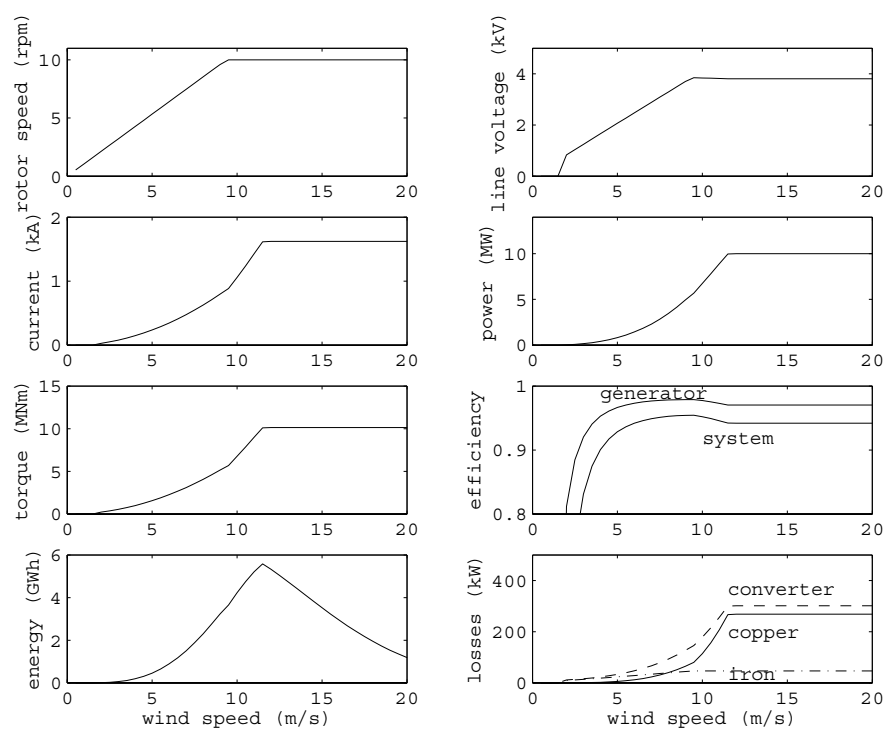

Fig. 6: Characteristics of a turbine with pitch control, a rated torque of 10 $\mathrm{MNm}$, a rated rotor speed of $10 \mathrm{rpm}$ and a rated power of $10 \mathrm{MW}$.
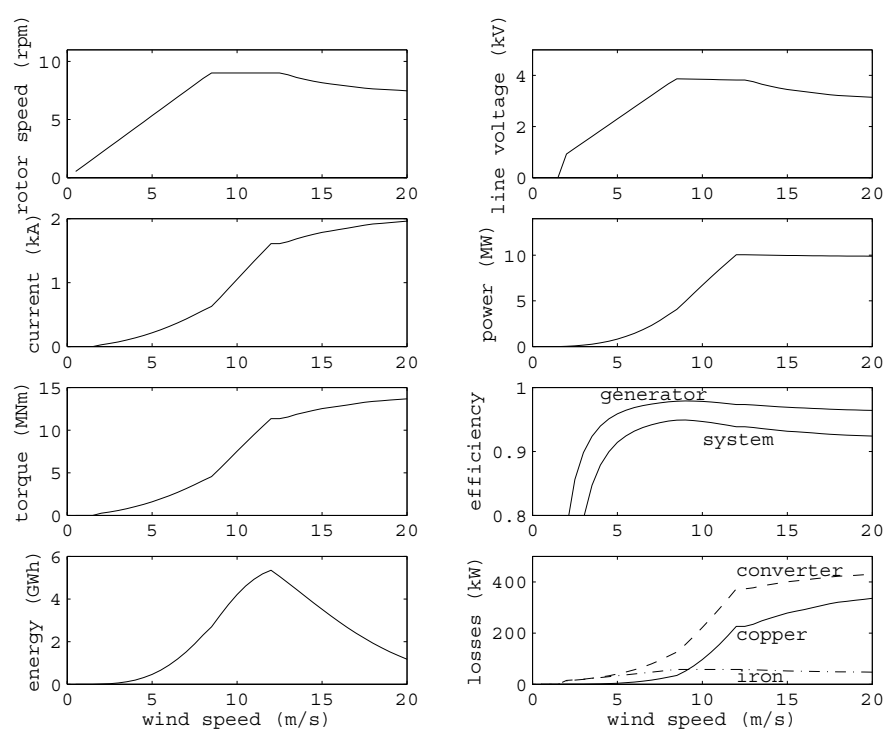

Fig. 7: Characteristics of a wind turbine with active speed stall control, a rated torque of $14 \mathrm{MNm}$, a rated rotor speed of $9 \mathrm{rpm}$ and a rated power of $10 \mathrm{MW}$. 
TABLE III

ANNUAl ENERGy For Pitch AND ACTIVE SPEED STAll CONTROL

\begin{tabular}{|c|c|c|}
\hline & pitch & active speed stall \\
\hline \multicolumn{3}{|c|}{ Annual energy (GWh) } \\
\hline copper losses (GWh) & 1.11 & 1.06 \\
\hline iron losses $(\mathrm{GWh})$ & 0.32 & 0.40 \\
\hline converter losses $(\mathrm{GWh})$ & 1.44 & 1.83 \\
\hline total losses $(\mathrm{GWh})$ & 2.87 & 3.29 \\
\hline energy yield (GWh) & 48.4 & 47.9 \\
\hline
\end{tabular}

\section{CONCLUSIONS}

This paper presents a rough $10 \mathrm{MW}$ permanent-magnet direct-drive generator design. Although this design is rough, it indicates that such a generator should be feasible. Further, pitch control and active speed stall control are compared. It is shown that for a thorough evaluation of active speed stall control, more knowledge is required mainly about changes in the wind speed. However, a considerable increase in generator system cost is necessary to enable active speed stall control if we want to keep the annual energy yield at a comparable level.

\section{REFERENCES}

[1] J.G. Slootweg, and E. de Vries, "Inside wind turbines - Fixed vs. variable speed," Renewable Energy World, pp. 30-40, 2003.

[2] H. Polinder, S.W.H. de Haan, J.G. Slootweg, and M.R. Dubois, "Basic operation principles and electrical conversion systems of wind turbines," EPE Journal, vol. 15, pp. 43-50, Dec. 2005.

[3] C. Versteegh, "Design of the Zephyros Z72 wind turbine with emphasis on the direct drive PM generator," in Proc. of the Nordic workshop on power and industrial electronics (NORPIE), Trondheim, 14-16 June 2004, paper number 68.

[4] R. Harrison, E. Hau, and H. Snel, Large wind turbines: design and economics. Chichester: Wiley, 2000.
[5] R.E. Wilson, and P.B.S. Lissaman, Applied aerodynamics of wind power machines, Oregon State University, USA, 1974.

[6] L.A.Viterna, and R.D. Corrigan, "Fixed pitch rotor performance of large horizontal axis wind turbines", in DOE/NASA Workshop on large HAWT's, Cleveland, Ohio, July, 1981.

[7] H. Polinder, F.F.A. van der Pijl, G.J. de Vilder, and P. Tavner, "Comparison of direct-drive and geared generator concepts for wind turbines", IEEE Transactions on Energy Conversion, vol. 21, pp. 725733, 2006.

[8] M.R. Dubois, "Optimized permanent magnet generator topologies for direct-drive wind turbines," Ph.D. dissertation, Delft University of Technology, The Netherlands, 2004.

[9] A. Grauers, "Design of direct-driven permanent-magnet generators for wind turbines", Ph.D. dissertation, Chalmers University of Technology, Göteburg, Sweden, 1996.

[10] E. Spooner, P. Gordon, J.R. Bumby and C. D. French, "Lightweight ironless-stator PM generators for direct-drive wind turbines," IEE Proceedings - Electric Power Applications, vol. 152, pp. 17-26, Jan. 2005.

[11] G. Bywaters, V. John, J. Lynch, P. Mattila, G. Norton, J. Stowell, M. Salata, O. Labath, A. Chertok, and D. Hablanian, Northern Power Systems WindPACT drive train alternative design study report, NREL, Golden, Colorado, report number NREL/SR-500-35524, 2004. Available: http://www.nrel.gov/docs/fy03osti/33196.pdf.

[12] A. Grauers, and P. Kasinathan, "Force density limits in low-speed PM machines due to temperature and reactance," IEEE Transactions on Energy Conversion, vol. 19, pp. 518-525, Sept. 2004.

[13] A. Grauers, P. Kasinathan, and E.S. Hamdi "Force density limits in lowspeed permanent magnet machines due saturation," IEEE Transactions on Energy Conversion, vol. 20, pp. 37-44, Mar. 2005.

[14] A.S. McDonald, M.A. Mueller, and H. Polinder, "Comparison of generator topologies for direct-drive wind turbines including structural mass," in Proceedings of the International Conference on Electrical Machines (ICEM06), Chania, 2-5 September 2006.

[15] H. Polinder, M.J. Hoeijmakers, and M. Scuotto, "Eddy-current losses in the solid back-iron of permanent-magnet machines with concentrated fractional pitch windings," in Proceedings of the third IEE International Conference on Power Electronics, Machines and Drives (PEMD06), Dublin, 4-6 April 2006, pp. 479-483. 